\title{
Parallel control structure scheme for load frequency controller design using direct synthesis approach
}

\author{
Anand Kumar, Md Nishat Anwar \\ Department of Electrical Engineering, National Institute of Technology Patna, India
}

\begin{tabular}{l}
\hline \hline Article Info \\
\hline Article history: \\
Received Jan 2, 2019 \\
Revised Aug 28, 2019 \\
Accepted Aug 30, 2019 \\
\hline Keywords: \\
IAE \\
Load frequency control (LFC) \\
Maximum sensitivity \\
parallel control structure \\
PID control
\end{tabular}

\begin{abstract}
This paper presents load frequency controller design for a single area as well as the multi-area thermal power system using direct synthesis approach with parallel control structure (PCS) scheme. The set-point and load frequency controller has been designed for frequency regulation and maintains tie-line power within a pre-specified limit for LFC power system. The proposed controller has been implemented for single-area, two-area, and four-area thermal power system for frequency regulation. The proposed method shows impressive simulation results compared with existed control method. The robustness of the proposed method has been examined with the help maximum sensitivity and parametric variation in the nominal power system.
\end{abstract}

Copyright $\odot 2020$ Institute of Advanced Engineering and Science. All rights reserved.

\section{Corresponding Author:}

Anand Kumar,

Departement of Electrical Engineering,

National Institute of Technology Patna,

Ashok Rajpath, Patna 800005, Bihar, India.

Email: anand.ee15@nitp.ac.in

\section{INTRODUCTION}

In power system, the frequency and tie-line power exchange deviate from its nominal value due to change in load and other abnormality. In load frequency control (LFC) retain the system frequency and tie-line power exchange between two areas at its nominal (pre-defined) value [1]. Many researchers have studied different design techniques for LFC in an interconnected power to maintain its frequency and tie-line power exchange at its pre-specified value i.e. available in the literature [2, 3].

A lot of research has been done in the LFC system for improvement in frequency deviation as well as tie-line power exchange between others area. Various controller design technique has been implemented for LFC system such as fractional order Proportional-Integral-Derivative (FOPID) [4], Proportional-integralderivative-acceleration (PIDA) [5, 6], Model predictive control (MPC) [7, 8], Fuzzy logic controller (FLC) [9, 10], internal model control (IMC) [11-14], cascade control [15, 16], sliding mode control (SMC) [17, 18], direct synthesis (DS) approach [19-21], variable structure control [22], active-disturbancerejection-control (ADRC) [23-24], Ho control [25], two degree of freedom (2DoF) control [26, 27], coefficient diagram method [28] etc.

Debbarma and Dutta [4] have proposed FOPID controller for LFC power system using flower pollination algorithm to obtain an optimum value of controller gain and the authors also utilize Electric vehicles as a source in frequency regulation of power system. Raju et al. [5] presents PID plus double derivative (PID+DD) controller based on ant-lion optimization technique for frequency regulation in multiarea thermal power system and provide improved performance in terms of settling time $\left(\mathrm{t}_{\mathrm{s}}\right)$, peak value. The authors also applied random step load at a different time in the three-area thermal power system and show better robustness of double derivative controller. Guha et al. [6] proposed double derivative PID controller with the application of multiverse optimization technique for frequency regulation in multi-area 
hydro-thermal power system and also consider generation rate constraint (GRC) and governor dead band (GDB) as non-linearity in the system model. Model predictive control is the modern technique for LFC in the power system. Linear matrix inequality (LMI) scheme is used to obtain MPC controller gain for LFC in three areas thermal power system by Shiroei et al. [7]. Ersdal et al. [8] has used MPC for frequency regulation in the Nordic power system using Kalman filter estimation technique. Sakia et al. [9] have proposed fuzzy logic plus integral double derivative (FIDD) controller for LFC in the three-area power system based on bacterial foraging algorithm. Fuzzy logic along with adaptive MPC technique has been proposed by Kayalvizhi and Kumar [10] for LFC in micro-grid.

Tan [11-13] presents a PID controller via 2DoF-IMC for frequency regulation problem in singlearea as well as a multi-area power system. The authors proposed Anti-GRC strategy to minimize the problem associated with the application of generation rate constraint in LFC [11]. Saxena and Hote [14] proposed a robust PID controller via internal model control (IMC) technique for LFC problem in a single area as well as the multi-area power system. Das et al. [15] have proposed cascade PD-PID controller for LFC in threearea thermal power system along with GRC using bat-algorithm and its response is superior to PI, PD, PID controller. Das et al. [16] proposed cascade PI-PD controller optimized using a flower-pollination algorithm and its performance are improved compared to classical PI, PD, PID controller. It shows that cascade control performance is better than the classical control technique. Sliding mode controller (SMC) has been designed by Vrdoljak et al. [17] for LFC in the power system based on state estimation approach and its controller also work in a non-minimum phase system. However, the sliding mode controller requires knowledge of full state feedback using state estimation technique. Mi et al. [18] proposed SMC to regulate frequency deviation and tie-line power exchange for the multi-area power system. The authors used Lyapunov stability to confirm the frequency is zero. Chen and Seborg [19] presents PID controller design using DS approach for first and second order system with time delay and its simulation results reveal the better disturbance rejection. Padhan and Majhi [20] present a new PID tuning method for LFC power system and its controller gains are obtained by Laurent series expansion of controller transfer function. Anwar and Pan [21] presents a PID controller for LFC in single as well as multi-area thermal power system using DS method in the frequency domain.

The variable control structure is used to design the Proportional-integral (PI) controller for LFC in the multi-area power system by Ray et al. [22]. Fu and Tan [23] present the ADRC technique for LFC in multi-area power system along with the communication delays. The ADRC controller gain is obtained using the IMC approach. Linear active disturbance rejection controller (LADRC) design has been proposed by Tang et al. [24] based on the hybrid particle swarm optimization approach for LFC in wind power plant. Peng et al. [25] proposed Hœ controller for LFC in the networked-based multi-area power system. Debbarma et al. [26] proposed 2DoF-proportional-integral with double derivative (2DoF-PIDD) controller for frequency regulation in the three-area thermal power system and controller parameter is obtained using the firefly algorithm (FA) technique. 2DoF-PID controller has been designed based on teaching learning-based optimization technique to regulate frequency deviation and tie-line power exchange for multi-area power system by Sahu et al. [27]. Load frequency controller has been designed by Bernard et al. [28] based on Coefficient diagram method (CDM) for two-area as well as three area power system.

The parallel control structure (PCS) is also named as 2DoF control structure has been discussed by Karungaran and Wenjian [29]. Figure 1 shows the generalized form of the PCS which has the ability to tune the controller to get the desired set-point response and load-disturbance response independently. The modified PCS scheme has been used to design a PID controller for an unstable process system with small time delay using DS approach by Ajmeri and Ali [30].

The above literature motivates to design a controller for LFC problem using PCS scheme. The nomenclature used in this paper is elaborated in Appendix A. In this paper, the PCS scheme has been used to design PID load frequency controller for a multi-area thermal power system using DS approach. The major contribution of this paper is as summarized below:

a. The new control structure to design a PID controller for LFC in the thermal power system.

b. The set-point controller and load frequency controller has been designed via pole-placement using direct synthesis approach.

c. Robustness of the controller has been analysed using uncertainty in the system parameter and random load has been applied to the system.

d. The proposed PID controller performance has been compared with existing PID design methods for a single area as well as the multi-area LFC system.

The whole paper is described in five chapters as follows: In chapter 1 described the introduction of the paper. The problem formulation of the multi-area thermal power system is elaborated in chapter 2 . Controller design methodology for LFC using DS approach has been discussed in chapter 3 . In chapter 4 discussed the simulation results of the different case studied of the power system and at last conclusion of the paper is described in chapter 5 . 


\section{PROBLEM FORMULATION}

The parallel control structure (PCS) as shown in Figure 1, which has the nominal model of the plant $\left(\mathrm{M}_{\mathrm{n}}\right)$ and actual model of the plant $\left(\mathrm{M}_{\mathrm{a}}\right)$ is considered to design set-point controller $\left(\mathrm{K}_{\mathrm{c} 1}\right)$ and loaddisturbance controller $\left(\mathrm{K}_{\mathrm{c} 2}\right)$ for load frequency control. The controller $\mathrm{K}_{\mathrm{c} 1}$ is used to regulate the set-point response of the system while $\mathrm{K}_{\mathrm{c} 2}$ is used to regulate load-disturbance of the system. The closed-loop response

$$
(\Delta \mathrm{f}) \text { of the PCS is given by } \Delta f=r\left(\frac{M_{a} K_{c 1}}{1+M_{n} K_{c 1}}\right)\left(\frac{1+M_{n} K_{c 2}}{1+M_{a} K_{c 2}}\right)+\left(\frac{M_{a}}{1+M_{a} K_{c 2}}\right) d
$$

Where $\mathrm{r}, \mathrm{d}, \Delta \mathrm{f}$ are the reference input, load disturbance and process output (change in frequency deviation) of the system. Under nominal condition $\left(\mathrm{M}_{\mathrm{a}}=\mathrm{M}_{\mathrm{n}}\right), \Delta \mathrm{f}$ may be represented as follows:

$$
\Delta f=r\left(\frac{M_{n} K_{c 1}}{1+M_{n} K_{c 1}}\right)+\left(\frac{M_{n}}{1+M_{n} K_{c 2}}\right) d
$$

\subsection{Single area power system}

The PID controller $\mathrm{K}_{\mathrm{ci}}(\mathrm{s})$ has been used to maintain the load frequency control of the thermal power system, which may be written as

$$
K_{c i}(s)=K_{p i}+\frac{K_{i i}}{s}+K_{d i} s(\mathrm{i}=1,2)
$$

Where $\mathrm{K}_{\mathrm{pi}}, \mathrm{K}_{\mathrm{ii}}, \mathrm{K}_{\mathrm{di}}$ are the proportional, integral, derivative constants of ith controller, respectively. The linearized model of the single-area thermal power system as shown in Figure 2, which is used to design the controller parameter. The transfer function of the power system model from $\mathrm{u}$ to $\Delta \mathrm{f}$ as shown in Figure 1 is

$$
\text { Written as } M_{n}=\frac{\Delta f}{u}=\frac{T_{g} T_{t} T_{p}}{1+T_{g} T_{t} T_{p} / R}
$$

Where $T_{g}, T_{t}, T_{p}$ are the transfer function of the governor, turbine \& generator and load respectively. $R$ is the speed regulation of the governor.

\subsection{Multi-area power system}

The controller design technique of single-area power system is extended to a multi-area power system. The change in frequency, as well as tie-line power exchange between areas, also varies from its pre-specified value due to load demand fluctuates in a multi-area power system. Area control error (ACE) is the combination of the small change in frequency deviation and tie-line power exchange and that ACE is minimized by using a controller gain parameter. The schematic block diagram of a multi-area power system is shown in Figure 3 . The ACE of the $i^{\text {th }}$ area may be represented as

$$
\mathrm{ACE}_{\mathrm{i}}=\Delta \mathrm{p}_{\mathrm{tie}, \mathrm{i}}+\beta_{\mathrm{i}} \Delta \mathrm{f}_{\mathrm{i}}
$$

Where $\beta_{\mathrm{i}}$ is the frequency bias factor. The tie-line power exchange $\left(\Delta \mathrm{p}_{\mathrm{tie}, \mathrm{i}}\right)$ between area $\mathrm{i}^{\text {th }}$ and other area is given by

$$
\Delta p_{\text {tiei }}=\sum_{\substack{j=1 \\ j \neq i}}^{N} \Delta p_{\text {tieij }}=\frac{1}{s}\left[\sum_{\substack{j=1 \\ j \neq i}}^{N} t_{i j} \Delta f_{i}-\sum_{\substack{j=1 \\ j \neq i}}^{N} t_{i j} \Delta f_{j}\right]
$$

Where $t_{i j}$ is the synchronizing power coefficient of the multi-area power system. The transfer function model of the multi-area power system can be represented as

$$
M_{n i}=\beta_{i} \frac{T_{g i} T_{t i} T_{p i}}{1+T_{g i} T_{t i} T_{p i} / R_{i}}
$$


The load frequency control in a multi-area power system is as same as single area power system where the tuning of each single area system is independently with consideration in the modified plant model as given in (7).

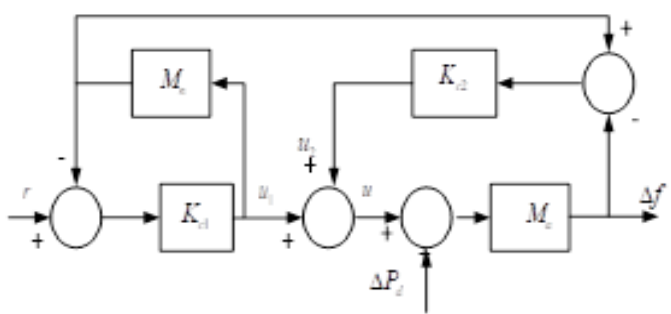

Figure 1. The schematic block diagram of the parallel control structure

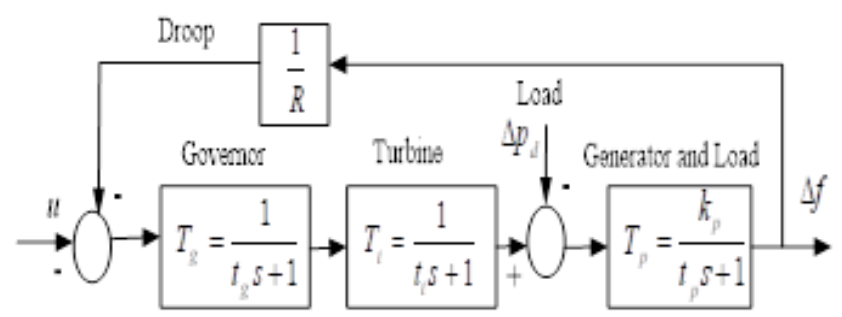

Figure 2. Single-area thermal power system

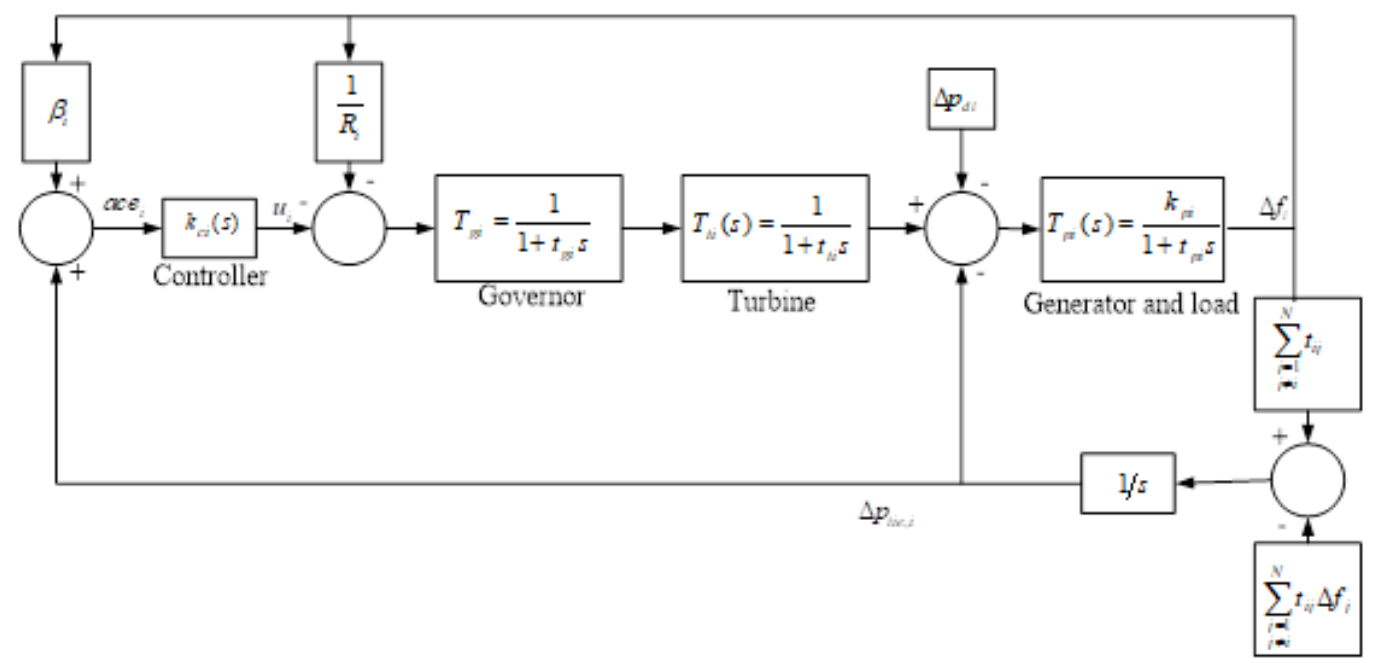

Figure 3. Schematic block diagram of the control area $i$

\section{CONTROLLER DESIGN METHODOLOGY}

In this paper, the parallel control structure (PCS) has been used to design PID controller using direct synthesis (DS) approach. The Parallel control structure (PCS) has also known as two degrees of freedom control structure [30] because the set-point controller and load disturbance controller are tuned independently of each other. Figure 1 shows a basic block diagram of the parallel control structure (PCS). In DS approach, a desired transfer function of the system is considered for the closed loop transfer function of the system. By approximating the desired transfer function with closed-loop transfer function of the system, a mathematical expression of the controller is obtained in terms of the desired transfer function and the closed-loop transfer function of the system. In PCS decouples the regulatory (load-disturbance rejection) problem from servomechanism (set-point tracking) problem.

\subsection{Set-point tracking controller $\left(\mathbf{K}_{\mathrm{c} 1}\right)$}

The desired set-point closed-loop transfer function Psp(s) (from $r$ to $\Delta f$ ) of the power system is considered as given by

$$
P_{s p}(s)=\frac{1}{(T s+1)^{n}}
$$

where $T$ is the time constant of the desired set-point reference model, $n$ is the order of the desired set-point reference model. 
From (2), the closed loop set-point transfer function $\left(\mathrm{P}_{\mathrm{r}, \mathrm{f}}\right)$ from ( $\Delta \mathrm{f}$ to $\mathrm{r}$ ) may be written as

$$
P_{r, f}=\frac{K_{c 1} M_{n}}{1+K_{c 1} M_{n}}
$$

The closed-loop characteristic equation from (9) may be written as

$$
1+K_{c 1} M_{n}=0
$$

In the direct synthesis (DS) technique, the controller has been designed by equating the closed loop set-point transfer function model with that of the desired set-point reference model, which may be written as

$$
P_{r, f}(s)=P_{s p}(s)
$$

The following aspects have been assumed to obtain such desired performance matching of LFC system using DS approach:

a. To obtain the desired transient response, the pole of the desired set-point reference model at $s=-1 / T$ may be assumed as the pole of the closed-loop system which results in the following equation.

$$
\begin{aligned}
& 1+K_{c 1} M_{n}=0 \text { for } s=-1 / T \\
& \text { Or, } K_{c 1}(s)=-\frac{1}{T_{g}(s) T_{t}(s) T_{p}(s)}-\frac{1}{R}
\end{aligned}
$$

Using (3), (13) may be written as

$$
K_{p 1}-T K_{i 1}-\frac{K_{d 1}}{T}=\left.\left[-\frac{1}{T_{g}(s) T_{t}(s) T_{p}(s)}-\frac{1}{R}\right]\right|_{s=-1 / T}=Z
$$

b. To obtain better steady state performance of the power system by matching the frequency response of the two systems at very small frequency point (say $\omega=0.001 \mathrm{rad} / \mathrm{s}$ ) which results in the following expression.

$$
P_{r, f}(j \omega) \cong P_{S P}(j \omega)
$$

The (15) may be written as

$$
\begin{aligned}
& \frac{K_{c 1}(j \omega) M_{n}(j \omega)}{1+K_{c 1}(j \omega) M_{n}(j \omega)} \cong P_{S P}(j \omega) \\
& K_{c 1} \cong \frac{P_{S P}(j \omega)}{M_{n}\left(1-P_{S P}(j \omega)\right)}
\end{aligned}
$$
as given by

The expression of PID controller parameter for LFC may be obtained by using (3) and (17)

$$
K_{p 1}+\frac{K_{i 1}}{j \omega}+K_{d 1} j \omega \cong\left(\frac{P_{S P}(j \omega)}{1-P_{S P}(j \omega)}\right) \frac{1}{T_{p}(j \omega) T_{g}(j \omega) T_{t}(j \omega)}-\frac{1}{R}
$$

Assuming $X \cong\left(\frac{P_{S P}(j \omega)}{1-P_{S P}(j \omega)}\right) \frac{1}{T_{p}(j \omega) T_{g}(j \omega) T_{t}(j \omega)}-\frac{1}{R}$, the (18) may be written as 


$$
K_{p 1}+j\left(K_{d 1} \omega-\frac{k_{i 1}}{\omega}\right)=\operatorname{Re}[X]+j \operatorname{Im}[X]
$$

By separating real and imaginary parts of (19), we get the following two equations as given by.

$$
\begin{aligned}
& K_{p 1}=\operatorname{Re}[X] \\
& K_{d 1} \omega+k_{i}\left(\frac{-1}{\omega}\right)=\operatorname{Im}[X]
\end{aligned}
$$

The (14), (20) and (21) may be arranged in matrix form as given by

$$
\left[\begin{array}{ccc}
1 & -T & -1 / T \\
1 & 0 & 0 \\
0 & \frac{-1}{\omega} & \omega
\end{array}\right]\left[\begin{array}{c}
K_{p 1} \\
K_{i 1} \\
K_{d 1}
\end{array}\right]=\left[\begin{array}{c}
Z \\
\operatorname{Re}[X] \\
\operatorname{Im}[X]
\end{array}\right]
$$

By solving the. (22), the PID controller gain for set-point response will be obtained.

\subsection{Load-disturbance controller $\left(K_{\mathrm{c} 2}\right)$}

The desired load-disturbance closed-loop transfer function $\mathrm{P}_{\mathrm{LD}}(\mathrm{s})$ (from $\Delta \mathrm{P}_{\mathrm{d}}$ to $\Delta f$ ) of the power system is considered as given by

$$
P_{L D}(s)=\frac{K s}{(T s+1)^{n}}
$$

where $T$ is the time constant of the desired load-disturbance reference model, $n$ is the order of the desired load-disturbance reference model and the constant gain $K=1 / K_{i 2}$. To ensure the frequency deviation of the system at steady state is zero due to one zero at the origin is placed in the desired load-disturbance reference model as in (23).

From (2), the closed loop load-disturbance transfer function $\left(\mathrm{P}_{\mathrm{d}, \mathrm{f}}\right)$ from $(\Delta \mathrm{f}$ to $\mathrm{d})$ may be written as

$$
P_{d, f}=\frac{M_{n}}{1+K_{c 2} M_{n}}
$$

The closed-loop characteristic equation from (24) may be written as

$$
1+K_{c 2} M_{n}=0
$$

In the direct synthesis (DS) technique, the controller has been designed by equating the closed loop load-disturbance transfer function model with that of the desired load-disturbance reference model, which may be written as

$$
P_{d, f}(s)=P_{L D}(s)
$$

The following aspects have been assumed to obtain such desired performance matching of LFC system using DS approach:

a. To obtain the desired transient response, the pole of the desired load-disturbance reference model at $s=-1 / T$ may be assumed as the pole of the closed-loop system which results in the following equation.

$$
\begin{aligned}
& 1+K_{c 2} M_{n}=0 \text { for } s=-1 / T \\
& \text { Or, } K_{c 2}(s)=-\frac{1}{T_{g}(s) T_{t}(s) T_{p}(s)}-\frac{1}{R}
\end{aligned}
$$


Using (3), (28) may be written as

$$
K_{p 2}-T K_{i 2}-\frac{K_{d 2}}{T}=\left.\left[-\frac{1}{T_{g}(s) T_{t}(s) T_{p}(s)}-\frac{1}{R}\right]\right|_{s=-1 / T}=Z
$$

b. To obtain better steady state performance of the power system by matching the frequency response of the two systems at very small frequency point (say $\omega=0.001 \mathrm{rad} / \mathrm{s}$ ) which results in the following expression.

$$
P_{d, f}(j \omega) \cong P_{L D}(j \omega)
$$

The (30) may be written as

$$
\begin{aligned}
& \frac{M_{n}(j \omega)}{1+K_{c 2}(j \omega) M_{n}(j \omega)} \cong P_{L D}(j \omega) \\
& K_{c 2} \cong \frac{1}{P_{L D}(j \omega)}-\frac{1}{M_{n}(j \omega)} \\
& \text { Or, } K_{c 2} \cong \frac{1}{P_{L D}(j \omega)}-\frac{1}{T_{p}(j \omega) T_{g}(j \omega) T_{t}(j \omega)}-\frac{1}{R}
\end{aligned}
$$
as given by

The expression of PID controller parameter for LFC may be obtained by using (3) and (33)

$$
K_{p 2}+\frac{K_{i 2}}{j \omega}+K_{d 2} j \omega \cong\left(\frac{K_{i 2}}{P_{l d}(j \omega)}\right)-\frac{1}{T_{p}(j \omega) T_{g}(j \omega) T_{t}(j \omega)}-\frac{1}{R}
$$

Assuming $W=\frac{1}{P_{l d}(j \omega)}=\frac{(1+T s)^{n}}{s}$ and $Y \cong \frac{1}{T_{p}(j \omega) T_{g}(j \omega) T_{t}(j \omega)}+\frac{1}{R}$, the (34) may be written as

$$
K_{p 2}+j\left(K_{d 2} \omega-\frac{k_{i 2}}{\omega}\right)=\left(K_{i 2} \operatorname{Re}[W]-\operatorname{Re}[Y]\right)+j\left(K_{i 2} \operatorname{Im}[W]-\operatorname{Im}[Y]\right)
$$

By separating real and imaginary parts of (35), we get the following two equations as given by.

$$
\begin{aligned}
& K_{p 2}-K_{i 2} \operatorname{Re}[W]=-\operatorname{Re}[Y] \\
& K_{d 2} \omega+k_{i 2}\left(\frac{-1}{\omega}-\operatorname{Im}[W]\right)=-\operatorname{Im}[Y]
\end{aligned}
$$

The (29), (36) and (37) may be arranged in matrix form as given by

$\left[\begin{array}{ccc}1 & -T & -1 / T \\ 1 & -\operatorname{Re}[W] & 0 \\ 0 & \frac{-1}{\omega}-\operatorname{Im}[W] & \omega\end{array}\right]\left[\begin{array}{c}K_{p 2} \\ K_{i 2} \\ K_{d 2}\end{array}\right]=\left[\begin{array}{c}Z \\ -\operatorname{Re}[Y] \\ -\operatorname{Im}[Y]\end{array}\right]$

By solving the (38), the PID controller gain for load-disturbance will be obtained. 


\section{SIMULATION RESULTS AND DISCUSSIONS:}

In this part, simulation results of a single area, two area and four-area thermal power system has been considered and show the major advantages of the proposed PID controller design method.

Case study 1: A single-area LFC power system with non-reheated thermal turbine (NRTT) [21] is considered with the following parameters $k_{p}=120, t_{p}=20, t_{t}=0.3, t_{g}=0.08, \mathrm{R}=2.4$. The desired setpoint and load disturbance transfer function model is considered with $\mathrm{T}=0.18, \mathrm{n}=3$. The proposed set-point PID controller is obtained as $\mathrm{K}_{\mathrm{cl}}(\mathrm{s})=0.1728+0.7870 / \mathrm{s}+0.1418 \mathrm{~s}$ and load- disturbance PID controller is obtained as $\mathrm{K}_{\mathrm{c} 2}(\mathrm{~s})=3.4001+7.0835 / \mathrm{s}+0.5187 \mathrm{~s}$. The load demand $\Delta \mathrm{P}_{\mathrm{d}}=0.01$ p.u. at $\mathrm{t}=0 \mathrm{sec}$ is applied in LFC power system to verify the performance of the proposed controller. The frequency regulation of the proposed PID controller is as shown in Figure 4 and its comparative performance of the proposed method is compared with that of prevalent designed techniques such as Anwar and Pan [21], Padhan and Majhi [20], Tan [11]. The detailed analysis of case study 1 is given in Table 1 . The simulation results of case study 1 reveal that the frequency deviation $(\Delta \mathrm{f})$, the integral of absolute error (IAE), and settling time $\left(\mathrm{t}_{\mathrm{s}}\right)$ are minimum value compared to Anwar and Pan [21], Padhan and Majhi [20], Tan [11]. The percentage improvement of peak value w.r.t Tan is as shown in Table 1 measured with the given formula as

$$
\% \text { improvement }=\frac{\text { peak value }(\text { reported })-\text { peak value }(\text { proposed })}{\text { peak value }(\text { reported })} \times 100
$$

To analyses, the robustness of the proposed PID controller, $-50 \%$ parameter variation in $k_{p}$ and $t_{p}$ of nominal plant model and frequency deviation of the perturbed plant is shown in Figure 5. The maximum sensitivity is defined as $M_{s}=\max _{0 \leq \omega \leq \infty} \mid 1 /\left[1+K_{c 2}(j \omega) M_{n}(j \omega)\right]$. The lowest value of $\mathbf{M}_{\mathrm{s}}$ indicates the robustness of the system.

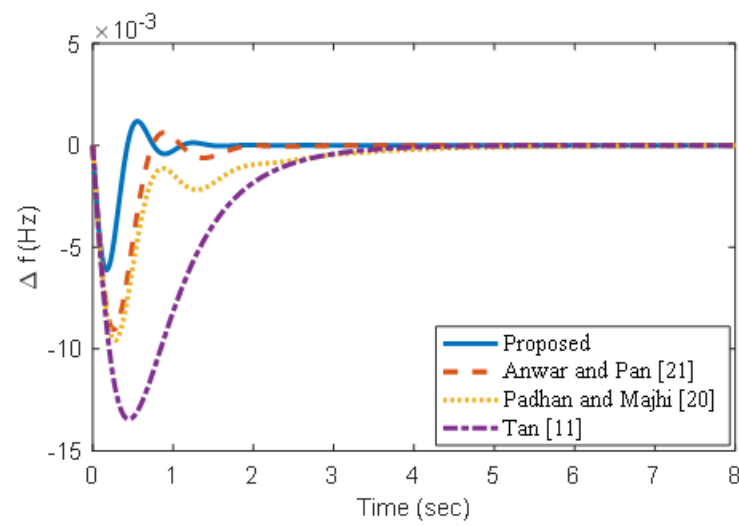

Figure 4. Frequency deviation response for case study 1 with nominal plant

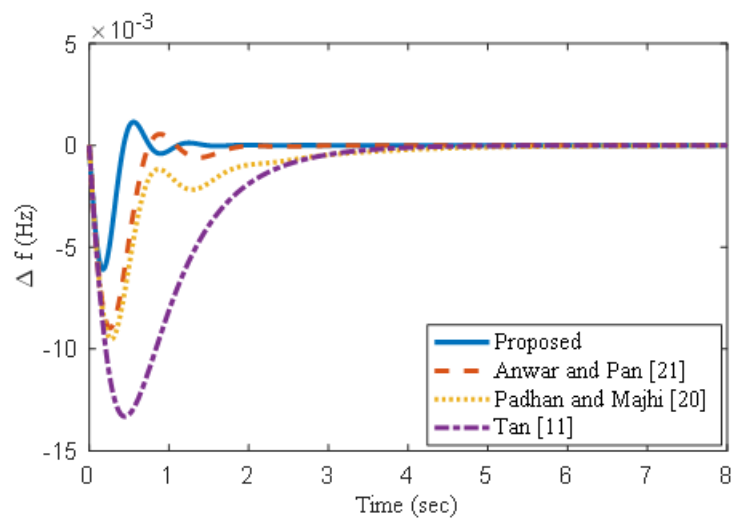

Figure 5. Frequency deviation response for case study 1 with $-50 \%$ variations in $k_{p}$ and $t_{p}$

Table 1. Comparative performance of case study 1

\begin{tabular}{|c|c|c|c|c|c|c|c|c|c|c|c|}
\hline \multirow[b]{2}{*}{ Method } & \multirow[b]{2}{*}{$K_{p 2}$} & \multirow[b]{2}{*}{$k_{i 2}$} & \multirow[b]{2}{*}{$K_{d 2}$} & \multirow[b]{2}{*}{$\mathrm{M}_{\mathrm{s}}$} & \multirow[b]{2}{*}{$\begin{array}{l}\text { Peak value } \\
\left(\mathrm{x} 10^{-3}\right)\end{array}$} & \multirow{2}{*}{$\begin{array}{l}\text { Nominal plant } \\
\% \text { Improvement } \\
\text { in term of Peak } \\
\text { value w.r.t Tan }\end{array}$} & \multicolumn{5}{|c|}{ Perturbed plant } \\
\hline & & & & & & & $\begin{array}{c}t_{\mathrm{s}} \\
(\mathrm{sec})\end{array}$ & $\begin{array}{c}\text { IAE } \\
\left(\mathrm{x} 10^{-3}\right)\end{array}$ & $\begin{array}{l}\text { Peak value } \\
\left(\mathrm{x} 10^{-3}\right)\end{array}$ & $\begin{array}{c}\mathrm{t}_{\mathrm{s}} \\
(\mathrm{sec})\end{array}$ & $\begin{array}{l}\text { IAE } \\
\left(\mathrm{x} 10^{-3}\right)\end{array}$ \\
\hline Proposed PID & 3.40 & 7.08 & 0.51 & 1.92 & 6.12 & 54.32 & 1.02 & 1.94 & 6.12 & 1.02 & 1.93 \\
\hline Anwar \& Pan [21] & 1.52 & 2.50 & 0.27 & 1.74 & 9.02 & 32.68 & 1.74 & 4.20 & 8.97 & 1.73 & 4.20 \\
\hline Padhan \& Majhi [20] & 1.49 & 1.30 & 0.235 & 1.77 & 9.6 & 28.35 & 4.07 & 7.68 & 9.52 & 4.09 & 7.68 \\
\hline $\operatorname{Tan}[11]$ & 0.40 & 0.63 & 0.183 & 1.24 & 13.4 & - & 3.51 & 15.8 & 13.3 & 3.58 & 15.8 \\
\hline
\end{tabular}

Case study 2: A single-area thermal power system with Re-heated turbine (RTD) [21] has been considered with the following parameters as given by

$$
k_{p}=120, t_{p}=20, t_{t}=0.3, t_{g}=0.08, \mathrm{R}=2.4, t_{r}=4.2 \text { and } \mathrm{c}=0.35
$$


The desired set-point and load disturbance transfer function model is considered with $\mathrm{T}=0.15, \mathrm{n}=3$. The proposed set-point PID controller is obtained as $\mathrm{K}_{\mathrm{cl}}(\mathrm{s})=0.2864+0.9444 / \mathrm{s}+0.3211 \mathrm{~s}$ and load- disturbance PID controller is obtained as $\mathrm{K}_{\mathrm{c} 2}(\mathrm{~s})=8.139+19.03 / \mathrm{s}+1.0921 \mathrm{~s}$. The load demand $\Delta \mathrm{P}_{\mathrm{d}}=0.01$ p.u.MW at $\mathrm{t}=0 \mathrm{sec}$ is applied in LFC power system to assure the performance of the proposed controller. The frequency regulation of the proposed PID controller is as shown in Figure 6 and its comparative performance of the proposed method is compared with that of prevalent designed techniques such as Anwar and Pan [21], Padhan and Majhi [20] and Tan [11]. The detailed analysis of case study 2 is given in Table 2. The simulation results of case study 2 reveal the frequency deviation $(\Delta \mathrm{f})$, the integral of absolute error (IAE), and settling time $\left(\mathrm{t}_{\mathrm{s}}\right)$ are much better than that of Anwar and Pan [21], Padhan and Majhi [20] and Tan [11]. The percentage improvement of peak value w.r.t Tan [11] is as shown in Table 2.

To analyses, the robustness of the proposed PID controller, $-50 \%$ parameter variation in $k_{p}$ and $t_{p}$ of nominal plant model and frequency deviation of the perturbed plant is shown in Figure 7. In case study 2 the maximum sensitivity $M_{s}$ is 2.37, which is lower than that of Anwar and Pan [21] Padhan and Majhi [20] and Tan [11].

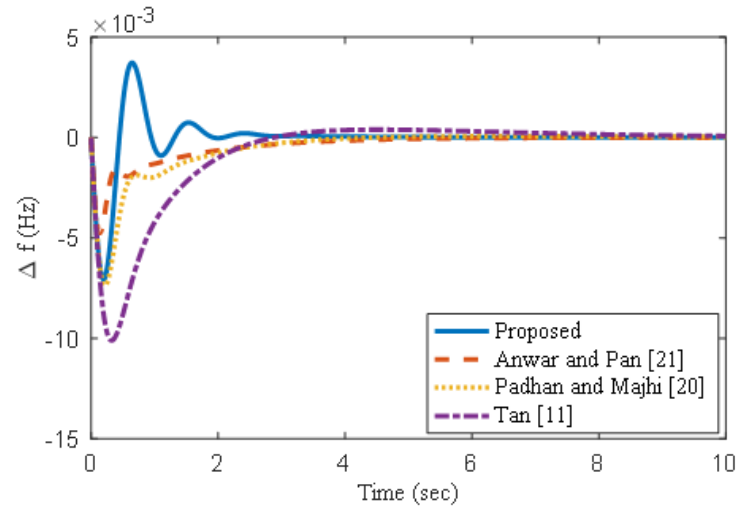

Figure 6. Frequency deviation response for case study 2 with nominal plant

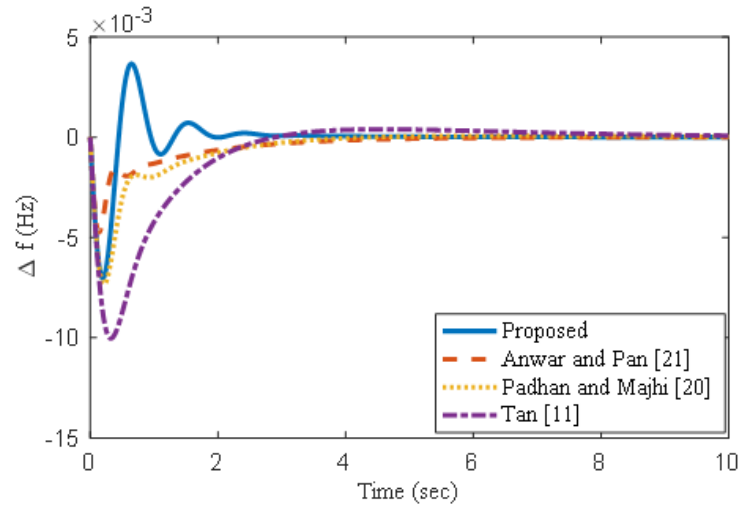

Figure 7. Frequency deviation response for case study 2 with $-50 \%$ variations in $k_{p}$ and $\tau_{p}$

Table 2. Comparative performance of case study 2

\begin{tabular}{|c|c|c|c|c|c|c|c|c|c|c|c|}
\hline \multirow[b]{2}{*}{ Method } & \multirow[b]{2}{*}{$K_{p 2}$} & \multirow[b]{2}{*}{$k_{i 2}$} & \multirow[b]{2}{*}{$K_{d 2}$} & \multirow[b]{2}{*}{$\mathrm{M}_{\mathrm{s}}$} & \multicolumn{4}{|c|}{ Nominal plant } & \multicolumn{3}{|c|}{ Perturbed plant } \\
\hline & & & & & $\begin{array}{l}\text { Peak } \\
\text { value } \\
\left(\times 10^{-3}\right) \\
\end{array}$ & $\begin{array}{l}\% \text { Improvement } \\
\text { in term of Peak } \\
\text { value w.r.t [20] }\end{array}$ & $\begin{array}{c}\mathrm{t}_{\mathrm{s}} \\
(\mathrm{sec})\end{array}$ & $\begin{array}{c}\text { IAE } \\
\left(\mathrm{x} 10^{-3}\right)\end{array}$ & $\begin{array}{c}\text { Peak } \\
\text { value } \\
\left(\times 10^{-3}\right)\end{array}$ & $\begin{array}{c}\mathrm{t}_{\mathrm{s}} \\
(\mathrm{sec})\end{array}$ & $\begin{array}{c}\text { IAE } \\
\left(\times 10^{-3}\right)\end{array}$ \\
\hline Anwar \& Pan [21] & 10.60 & 2.50 & 2.57 & 1.76 & 4.75 & 52.5 & 3.64 & 4.0 & 4.73 & 3.65 & 4.0 \\
\hline Padhan \& Majhi [20] & 6.16 & 1.93 & 1.16 & 1.61 & 7.38 & 26.2 & 3.23 & 5.80 & 7.34 & 3.24 & 5.80 \\
\hline $\operatorname{Tan}[11]$ & 2.79 & 1.27 & 0.787 & 1.32 & 10.0 & - & 7.4 & 11.4 & 10.0 & 7.4 & 11.4 \\
\hline
\end{tabular}

Case study 3: A two area power system with NRT has been reported from [21] with the following system parameter as $k_{p 1}=k_{p 2}=120, \quad t_{p 1}=t_{p 2}=20, \quad t_{t 1}=t_{t 2}=0.3, \quad t_{g 1}=t_{g 2}=0.08, \quad \mathrm{R}_{1}=\mathrm{R}_{2}=2.4$, $\beta_{1}=\beta_{2}=0.425$.

The desired set-point and load disturbance transfer function model is considered with $\mathrm{T}=0.18, \mathrm{n}=3$. The proposed set-point PID controller is obtained as $\mathrm{K}_{\mathrm{cl}}(\mathrm{s})=-0.4065+1.8517 / \mathrm{s}+0.3336 \mathrm{~s}$ and loaddisturbance PID controller is obtained as $\mathrm{K}_{\mathrm{c} 2}(\mathrm{~s})=8+16.65 / \mathrm{s}+1.22 \mathrm{~s}$. The load demand $\Delta \mathrm{P}_{\mathrm{d}}=0.01$ p.u. at $\mathrm{t}=0 \mathrm{sec}$ is applied in LFC power system to verify the performance of the proposed controller. The frequency regulation of the proposed PID controller is as shown in Figures 8, 9, 10 and the simulation results of the proposed design method are compared with that of Anwar and Pan [21], Tan [11]. The detailed analysis of case study 3 is described in Table 3. The simulation results of case study 4 reveal that the percent overshoot $(\% \mathrm{OS})$ in frequency deviation $(\Delta \mathrm{f})$, the integral of absolute error (IAE), and settling time $\left(\mathrm{t}_{\mathrm{s}}\right)$ are better than that of Anwar and Pan [21], Tan [11] in each area. The percent overshoot (\%OS) in tie-line power, settling time $\left(\mathrm{t}_{\mathrm{s}}\right)$, IAE is improved than that of Anwar and Pan [21] and Tan [11]. In case study 3 the maximum sensitivity $M_{s}$ is 2.37, which is higher than that of Anwar and Pan [21] and Tan [11]. 


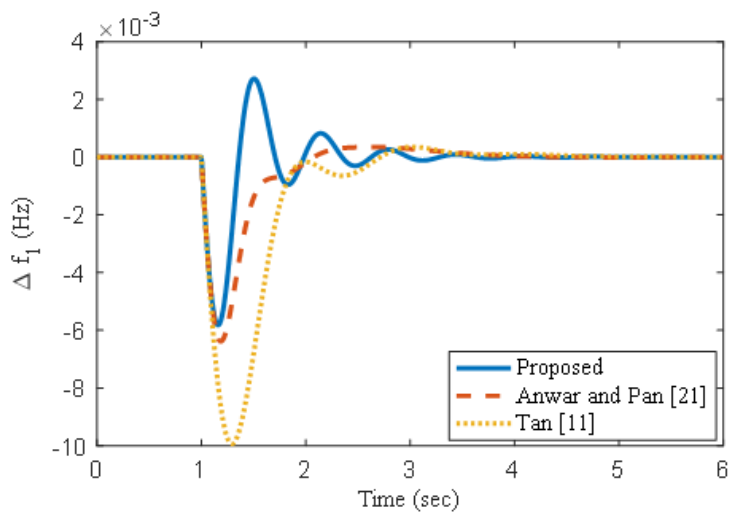

Figure 8. Frequency regulation of area 1 for case study 3

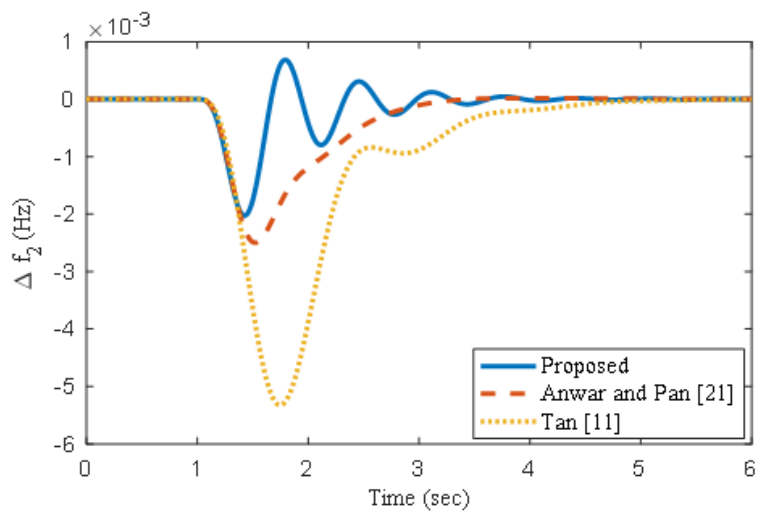

Figure 9. Frequency regulation of area 2 for case study 3

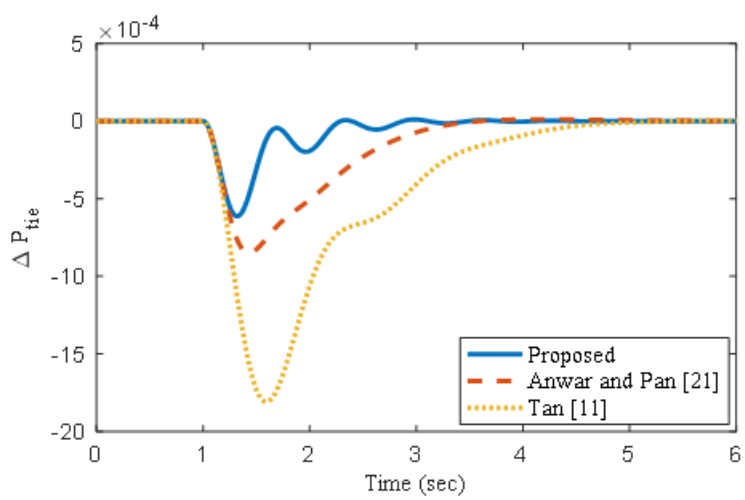

Figure 10. Tie-line power exchange between area $1 \& 2$ for case 3

Table 3. Comparative performance of case study 3

\begin{tabular}{|c|c|c|c|c|c|c|c|c|c|c|c|}
\hline \multirow{3}{*}{ Method } & \multirow{3}{*}{$K_{p 2}$} & \multirow{3}{*}{$K_{i 2}$} & \multirow{3}{*}{$\mathrm{M}_{\mathrm{s}}$} & \multicolumn{3}{|c|}{ Area 1} & \multicolumn{3}{|c|}{ Area 2} & \multicolumn{2}{|c|}{ Tie-line power } \\
\hline & & & & \multicolumn{3}{|c|}{$\Delta f_{1}$} & \multicolumn{3}{|c|}{$\Delta f_{2}$} & \multicolumn{2}{|c|}{$\Delta P_{t i e}$} \\
\hline & & & & $\begin{array}{c}\% \mathrm{OS} \\
\left(\mathrm{x} 10^{-3}\right) \\
\end{array}$ & $\begin{array}{c}\mathrm{t}_{\mathrm{s}} \\
(\mathrm{sec})\end{array}$ & $\begin{array}{l}\text { IAE } \\
\left(\times 10^{-3}\right)\end{array}$ & $\begin{array}{c}\% \mathrm{OS} \\
\left(\mathrm{x} 10^{-3}\right)\end{array}$ & $t_{s}$ & $\begin{array}{l}\mathrm{IAE} \\
\left(\mathrm{x} 10^{-3}\right)\end{array}$ & $\begin{array}{c}\% \text { OS } t_{s} \\
\left(x 10^{-4}\right)(\mathrm{sec})\end{array}$ & $\begin{array}{c}\mathrm{IAE} \\
\left(\mathrm{x} 10^{-3}\right)\end{array}$ \\
\hline Proposed PID & 8 & 16.651 .22 & 2.37 & 5.82 & 2.86 & 1.10 & 2.02 & 2.86 & 0.35 & $0.63 \quad 1.54$ & 0.30 \\
\hline Anwar and Pan [21] & 3.55 & $5.95 \quad 1.22$ & 1.75 & 6.38 & 3.2 & 1.80 & 2.50 & 2.82 & 0.17 & 8.50 & 0.87 \\
\hline $\operatorname{Tan}[11]$ & 1.569 & 2.39660 .525 & 1.43 & 9.92 & 3.32 & 4.18 & 5.32 & 3.9 & 0.65 & $18.06 \quad 3.42$ & 2.09 \\
\hline
\end{tabular}

Case study 4: A four area LFC power system with NRTT as shown in Figure 11 has been considered from [13] with the following system parameter

Area No. 1: $k_{p 1}=120, t_{p 1}=20, t_{t 1}=0.3, t_{g 1}=0.08, \mathrm{R}_{1}=2.4$, Area No. $2: k_{p 2}=112.5, t_{p 2}=25$, $t_{t 2}=0.33, t_{g 2}=0.072, \mathrm{R}_{2}=2.7$, Area No. 3: $k_{p 3}=125, t_{p 3}=20, t_{t 3}=0.35, t_{g 3}=0.07, \mathrm{R}_{3}=2.5$ Area No. $4: k_{p 4}=115, t_{p 4}=15, t_{t 4}=0.375, t_{g 4}=0.085, \mathrm{R}_{4}=2.0$

The synchronizing constants are $t_{12}=t_{13}=t_{14}=t_{21}=t_{23}=t_{32}=t_{41}=0.545$ and the frequency bias constants are $\beta_{1}=\beta_{2}=\beta_{3}=\beta_{4}=0.425$. 


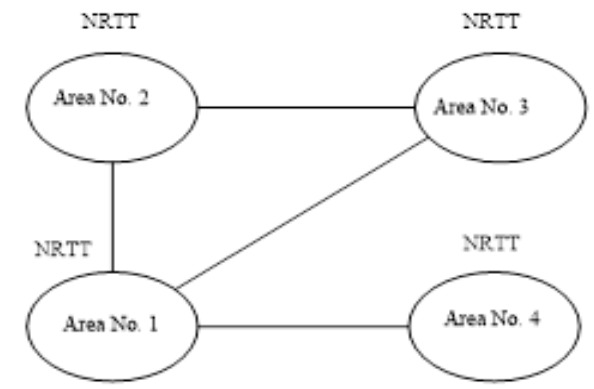

Figure 11. Four-area non-reheat thermal turbine (NRTT) system

A four-area interconnected thermal power system is studied to demonstrate the advantage of the proposed controller. The area no.1, 2, 3 are interconnected to each other, while the area no. 4 is connected with area 1 only and each area in power is non-reheated thermal turbine (NRTT). The desired set-point and load disturbance transfer function model for each area are considered with $\mathrm{T}=0.30, \mathrm{n}=3$. The proposed set-point PID controller for each area is obtained as

$$
\begin{aligned}
& K_{c 11}(s)=0.0470+\frac{0.4722}{s}+0.096 s, K_{c 12}(s)=0.1245+\frac{0.4214}{s}+0.1272 s, \\
& K_{c 13}(s)=0.0455+\frac{0.4533}{s}+0.1130 s, K_{c 14}(s)=-0.0202+\frac{0.5652}{s}+0.1160 s
\end{aligned}
$$

The load- disturbance PID controller for each area is obtained as

$$
\begin{aligned}
& K_{c 21}(s)=1.2483+\frac{1.8599}{s}+0.3322 s, K_{c 22}(s)=2.0189+\frac{2.6646}{s}+0.4937 s \\
& K_{c 23}(s)=1.403+\frac{2.0122}{s}+0.3799 s, K_{c 24}(s)=1.0386+\frac{1.7192}{s}+0.3298 s
\end{aligned}
$$

The simulation results of the proposed controller are observed by applying load demand $\Delta \mathrm{P}_{\mathrm{d}}=0.01$ p.u.MW at $\mathrm{t}=1 \mathrm{sec}$ in an area no. 1,2 and load demand $\Delta \mathrm{P}_{\mathrm{d}}=0.01$ p.u.MW at $\mathrm{t}=20 \mathrm{sec}$ in an area no. 3,4 simultaneously. The change in frequency deviation is shown in Figure 12 while tie-line power between interconnected-area is shown in Figure 13. The simulation result of the proposed controller as shown in Figure 12 and Figure 13 is compared with Tan [13] and observed that the proposed method is better than Tan [13] in terms of frequency deviation and settling time.
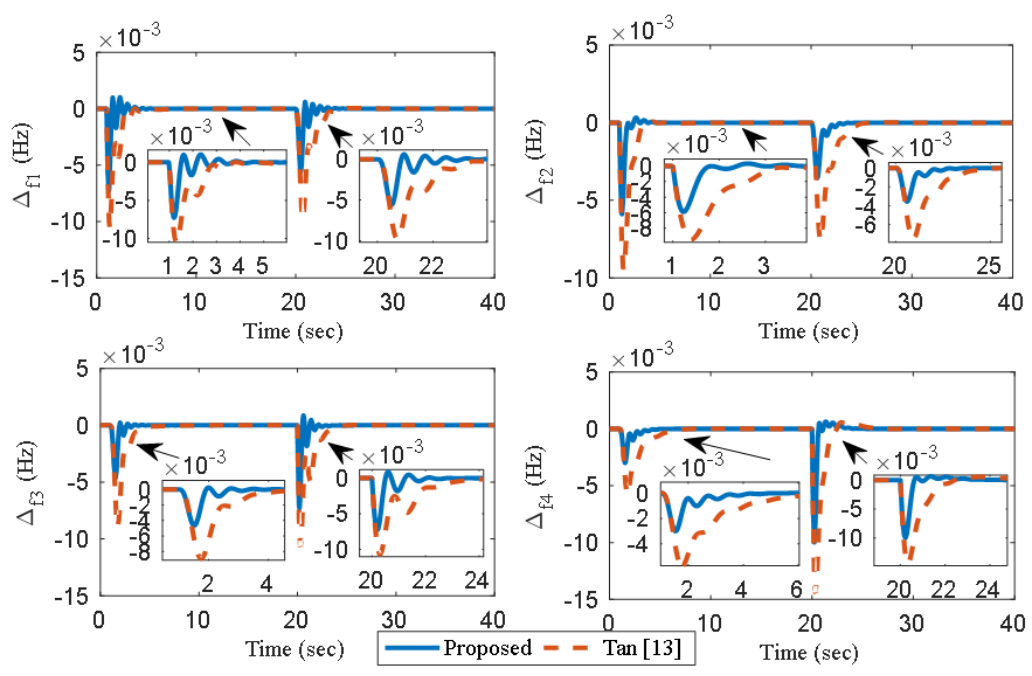

Figure 12. Frequency regulation of four area power system in case study 4 

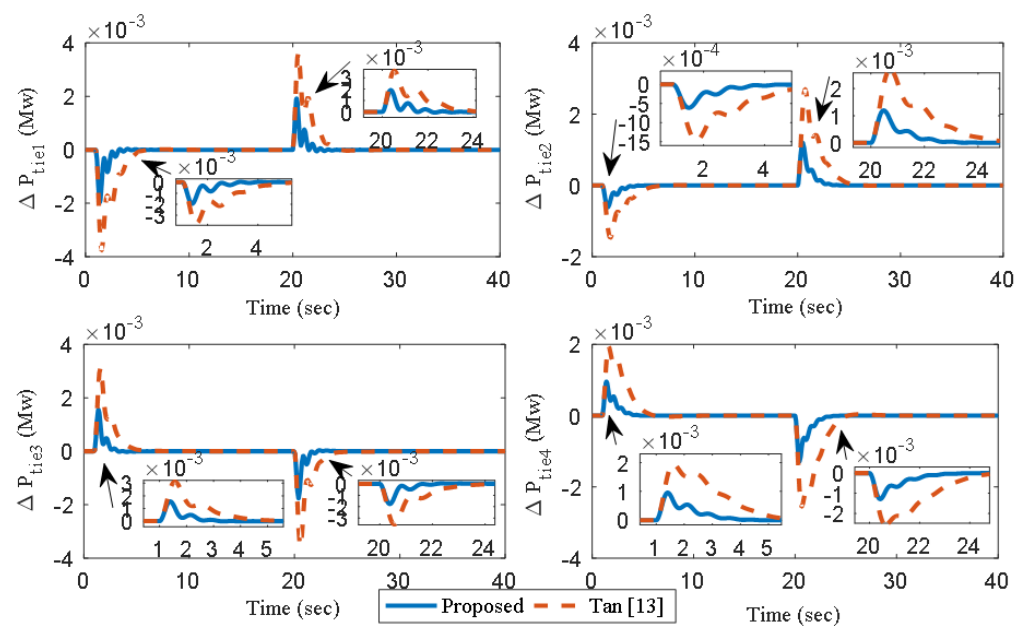

Figure 13. Tie-line power exchange of four-area power system in case 4

\subsection{Random loading pattern (RLP)}

To assure robustness of the proposed PID controller method, different step change in load applied at particular interval of time in case study 1 . The simulation results as shown in Figure 14 for case study 1 by applying random step change in load. The simulation results reveal the percent overshoot and settling time is improved even that high magnitude of step load apply in LFC power system. Thus, the proposed design technique is effective in LFC power system

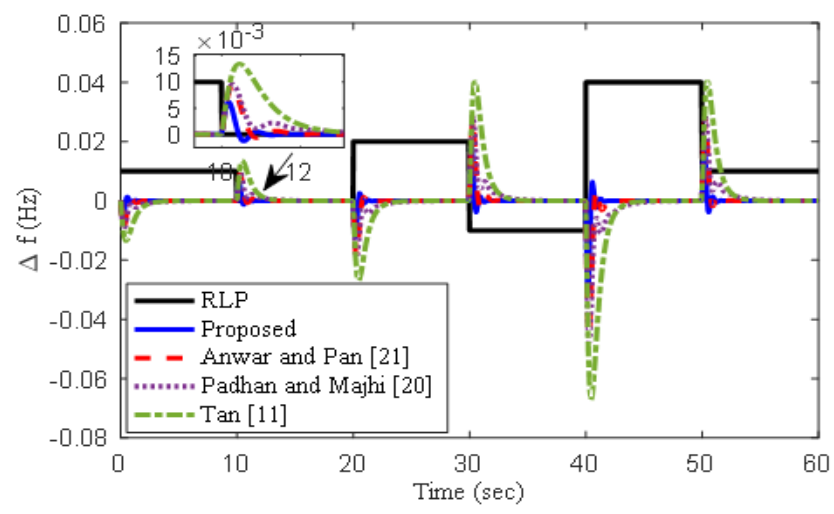

Figure 14. Frequency regulation of case study 1 with RLP

\section{CONCLUSION}

In this article, the PCS scheme has been used to design the set-point and load-frequency controller for a single-area and the multi-area power system using the DS approach. The proposed technique has been considered for single-area reheat as well as non-reheated thermal turbine power system, two-area non-reheated system, four-area non-reheated system. Proposed technique show better simulation response in terms of percent overshoot, settling time, and IAE for the nominal system as well as the perturbed system. Robustness of the proposed method has been analyzed with system parameter variation and the random load applied at a particular time in the LFC power system. The main advantages of the proposed technique are to improved percent overshoot and settling time compared to standard reported literature.

\section{REFERENCES}

[1] Kundur P., power system stability and control, McGraw-Hill, 1994.

[2] P. Kumar and D. P. Kothari, "Recent Philosophies of Automatic Generation Control Strategies in Power Systems," IEEE Trans. Power Syst., vol. 20(1), pp. 346-357, 2005. 
[3] A. Pappachen and A. Peer Fathima, "Critical research areas on load frequency control issues in a deregulated power system: A state-of-the-art-of-review," Renew. Sustain. Energy Rev., vol. 72(January), pp. 166-177, 2017.

[4] S. Debbarma and A. Dutta, "Utilizing Electric Vehicles for LFC in Restructured Power Systems Using Fractional Order Controller," vol. 8(6), pp. 2554-2564, 2017.

[5] M. Raju, L. C. Saikia, and N. Sinha., "Automatic generation control of a multi-area system using ant lion optimizer algorithm based PID plus second order derivative controller," Int. J. Electr. Power Energy Syst., vol. 80, pp. 52-63, 2016.

[6] D. Guha, P. K. Roy, and S. Banerjee., "Multi-verse optimisation: A novel method for solution of load frequency control problem in power system," IET Gener. Transm. Distrib., vol. 11(14), 2017.

[7] M. Shiroei, M. R. Toulabi, and A. M. Ranjbar., "Robust multivariable predictive based load frequency control considering generation rate constraint," Int. J. Electr. Power Energy Syst., vol. 46(1), pp. 405-413, 2013.

[8] A. M. Ersdal, L. Imsland, and K. Uhlen., "Model Predictive Load-Frequency Control," IEEE Trans. Power Syst., vol. 31(1), pp. 777-785, 2016.

[9] L. C. Saikia, N. Sinha, and J. Nanda., "Maiden application of bacterial foraging based fuzzy IDD controller in AGC of a multi-area hydrothermal system," Int. J. Electr. Power Energy Syst., vol. 45(1), pp. 98-106, 2013.

[10] S. Kayalvizhi and D. M. Vinod Kumar, "Load frequency control of an isolated micro grid using fuzzy adaptive model predictive control," IEEE Access, vol. 5, pp. 16241-16251, 2017.

[11] W. Tan., "Tuning of PID load frequency controller for power systems," Energy Convers. Manag., vol. 50(6), pp. 1465-1472, 2009.

[12] W. Tan., "Unified tuning of PID load frequency controller for power systems via IMC," IEEE Trans. Power Syst., vol. 25(1), pp. 341-350, 2010.

[13] W. Tan, "Decentralized load frequency controller analysis and tuning for multi-area power systems," Energy Convers. Manag., vol. 52(5), pp. 2015-2023, 2011.

[14] S. Saxena and Y. V. Hote, "Stabilization of perturbed system via IMC: An application to load frequency control," Control Eng. Pract., vol. 64(January), pp. 61-73, 2017.

[15] P. Dash, L. C. Saikia, N. Sinha., "Automatic generation control of multi area thermal system using Bat algorithm optimized PD - PID cascade controller," Int. J. Electr. POWER ENERGY Syst., vol. 68, pp. 364-372, 2015.

[16] P. Dash, L. Chandra, and N. Sinha., "Flower Pollination Algorithm Optimized PI-PD Cascade Controller in Automatic Generation Control of a Multi-area Power System," Int. J. Electr. Power Energy Syst., vol. 82, pp. 19-28, 2016.

[17] K. Vrdoljak, N. Perić, and I. Petrović., "Sliding mode based load-frequency control in power systems," Electr. Power Syst. Res., vol. 80(5), pp. 514-527, 2010.

[18] Y. Mi, Y. Fu, C. Wang, and P. Wang., "Decentralized sliding mode load frequency control for multi-area power systems," IEEE Trans. Power Syst., vol. 28(4), pp. 4301-4309, 2013.

[19] D. Chen and D. E. Seborg, "PI/PID Controller Design Based on Direct Synthesis and Disturbance Rejection," Ind. Eng. Chem. Res., vol. 41(19), pp. 4807-4822, 2002.

[20] D. G. Padhan and S. Majhi, "A new control scheme for PID load frequency controller of single-area and multi-area power systems," ISA Trans., vol. 52(2), pp. 242-251, 2013.

[21] M. N. Anwar and S. Pan, "A new PID load frequency controller design method in frequency domain through direct synthesis approach," Int. J. Electr. Power Energy Syst., vol. 67, pp. 560-569, 2015.

[22] G. Ray, S. Dey, and T. K. Bhattacharyya., "Multi-Area Load Frequency Control of Power Systems: A Decentralized Variable Structure Approach," Electr. Power Components Syst., vol. 33(3), pp. 315-331, 2004.

[23] C. Fu and W. Tan, "Decentralised load frequency control for power systems with communication delays via active disturbance rejection," IET Generation, Transmission \& Distribution, vol. 12, pp. 6, pp. 1397 - 1403, 2018.

[24] Y. Tang, Y. Bai, C. Huang, and B. Du., "Linear active disturbance rejection-based load frequency control concerning high penetration of wind energy," Energy Convers. Manag., vol. 95, pp. 259-271, 2015.

[25] C. Peng, J. Zhang, and H. Yan., "Adaptive Event-Triggering $\$\{\mathrm{H}\}_{-}\{$linfty $\} \$$ Load Frequency Control for Network-Based Power Systems," IEEE Trans. Ind. Electron., vol. 65(2), pp. 1685-1694, 2018.

[26] S. Debbarma, L. Chandra, and N. Sinha., "Robust two-degree-of-freedom controller for automatic generation control of multi-area system," Int. J. Electr. Power Energy Syst., vol. 63, pp. 878-886, 2014.

[27] R. K. Sahu, S. Panda, U. K. Rout, and D. K. Sahoo., "Teaching learning based optimization algorithm for automatic generation control of power system using 2-DOF PID controller," Int. J. Electr. Power Energy Syst., vol. 77, pp. 287-301, 2016.

[28] M. Z. Bernard, T. H. Mohamed, Y. S. Qudaih, and Y. Mitani, "Decentralized load frequency control in an interconnected power system using Coefficient Diagram Method," Int. J. Electr. Power Energy Syst., vol. 63, pp. 165-172, 2014.

[29] G. Karunagaran and C. Wenjian, "The Parallel Control Structure for Transparent Online Tuning," Journal of Process Control, vol. 21(7), pp. 1072-1079, 2011.

[30] M. Ajmeri and A. Ali, "Two degree of freedom control scheme for unstable processes with small time delay," ISA Trans., vol. 56, pp. 308-326, 2015. 


\section{BIOGRAPHIES OF AUTHORS}

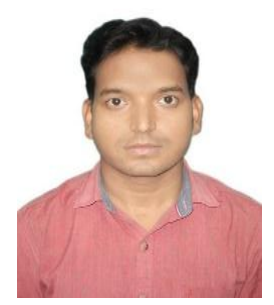

Anand Kumar: Received Bachelor of Engineering degree in Electrical and Electronic Engineering from OIST, Bhopal, India, in 2013 and currently pursuing M.Tech-PhD dual degree from NIT, Patna in Department of Electrical Engineering since 2015. His research interest includes Load frequency control, Automatic voltage regulator, PID controller, PIDA controller.

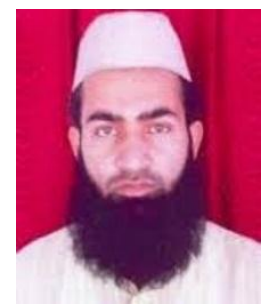

Md Nishat Anwar: He obtained his bachelor and master degree in Electrical Engineering from AMU, Aligarh, India. He obtained his Ph.D. from IIT (ISM), Dhanbad, India in 2015. He has teaching experience of 4 years and currently working as an Assistant Professor in the Department of Electrical Engineering, NIT Patna, India. His research interests include industrial control and automation, PID controller, model predictive control and have several masters and Ph.D. students working under him. His publication includes 4 papers in referred journals, 12 papers in international conferences and 5 papers in national conferences. 